\title{
Influence of the Interaction Strength between Supramolecular Complexes on the Topography of Neutral Polymer Multilayer Films
}

Lydie Séon, ${ }^{\dagger \neq, \$}$ Audrey Parat, ${ }^{*, \&}$ Fabien Gaudière, ${ }^{\dagger}$ Jean-Claude Voegel, ${ }^{\ddagger}, 8$ Rachel Auzély-Velty, Philippe Lorchat, ${ }^{\dagger}$ Liliane Coche-Guérente, ${ }^{\perp, \#}$ Bernard Senger, ${ }^{\ddagger}, \S$ Pierre Schaaf, ${ }^{\dagger, \pm}, \$, \nabla, O$, Loïc Jierry, $*, \nabla, \nabla, O, \pi$ and Fouzia Boulmedais, $*, \nabla, \nabla, \pi$

${ }^{\dagger}$ Institut Charles Sadron, Centre National de la Recherche Scientifique, Université de Strasbourg, UPR 22, 23 rue du Loess, BP 84047, 67034, Strasbourg Cedex 2, France

‡INSERM, UMR-S 1121, “Biomatériaux et Bioingénierie”, 11 rue Humann, 67085 Strasbourg Cedex, France

${ }^{\S}$ Faculté de Chirurgie Dentaire, Université de Strasbourg, 8 rue Sainte Elisabeth, 67000, Strasbourg, France

"Centre de Recherches sur les Macromolécules Végétales, affiliated with Université Joseph Fourier, 601 rue de la Chimie, 38041 Grenoble, France

${ }^{\perp}$ Université Grenoble Alpes, DCM UMR 5250, F-38000 Grenoble, France

${ }^{\#}$ CNRS, DCM UMR 5250, F-38000 Grenoble, France

${ }^{\nabla}$ International Center for Frontier Research in Chemistry, 8 allée Gaspard Monge, 67083 Strasbourg, France

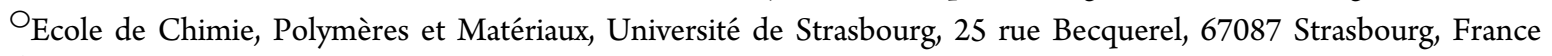

Institut Universitaire de France, 103 boulevard Saint-Michel, 75005 Paris, France

${ }^{I I}$ Institut d'Etudes Avancées de l’Université de Strasbourg, 5 allée du Général Rouvillois, 67083 Strasbourg, France

Supporting Information

ABSTRACT: Step-by-step polymer film buildup processes lead to polymer coatings, e.g., polyelectrolyte multilayers, of various structures ranging from continuous smooth films to droplet like discontinuous coatings. Yet, the origin of these different behaviors depending upon the system is not yet known. This study is a first attempt to rationalize the evolution of the coating structure as a function of the strength of the interactions between the polymers constituting the film. We investigated the influence of the strength of noncovalent hostguest interactions between cyclodextrin (CD) and pyrene (Py), ferrocene $(\mathrm{Fc})$ or adamantane $(\mathrm{Ad})$ on the structure of neutral poly(N-hydroxypropylmethacrylamide) (PHPMA) multilayers films formed in a step-by-step manner. In solution, the strength of the inclusion complex (measured by $\log K$ where $K$ is the complex association constant) is increasing in the order $\mathrm{Py} / \beta$ - $\mathrm{CD}<\mathrm{Fc} / \beta$ - $\mathrm{CD}<\mathrm{Ad} / \beta$ - $\mathrm{CD}$ and can be further varied in the presence of different sodium salts at different ionic strengths. Depending upon this strength, the buildup process is limited to the formation of isolated aggregates for PHPMA-CD/PHPMAPy, leading to smooth continuous films for PHPMA-CD/PHPMA-Fc and to droplet-like films, not entirely covering the substrate, for PHPMA-CD/PHPMA-Ad. To study the influence of the strength of the host-guest interactions on the film topography, PHPMA-CD/PHPMA-Fc films were built in the presence of different sodium salts at different ionic strengths. For low host-guest interactions, only isolated aggregates are formed on the substrate. As the strength of the host-guest interactions increases (increase of $\log K$ ), the formed films go through a droplet-like structure, before becoming continuous but rough for stronger interactions. When the interaction strength is further increased, the roughness of the films decreases, leading to a smooth continuous film before becoming rough again at still higher interaction strength. Smooth continuous multilayers seem thus to be obtained for an optimal range of the interaction strength.

\section{INTRODUCTION}

Step-by-step film buildup processes constitute a very general way to functionalize surfaces. ${ }^{1,2}$ Multilayer films are obtained by alternating adsorption of two types of interacting species on inorganic $^{3-5}$ or organic ${ }^{6,7}$ substrates. Deposition of polymer
Received: April 11, 2014

Revised: May 12, 2014

Published: May 12, 2014 
Scheme 1. Chemical Structures of PHPMA-Ad, PHPMA-Fc, PHPMA-Py, PHPMA-CD, and PAH-CD

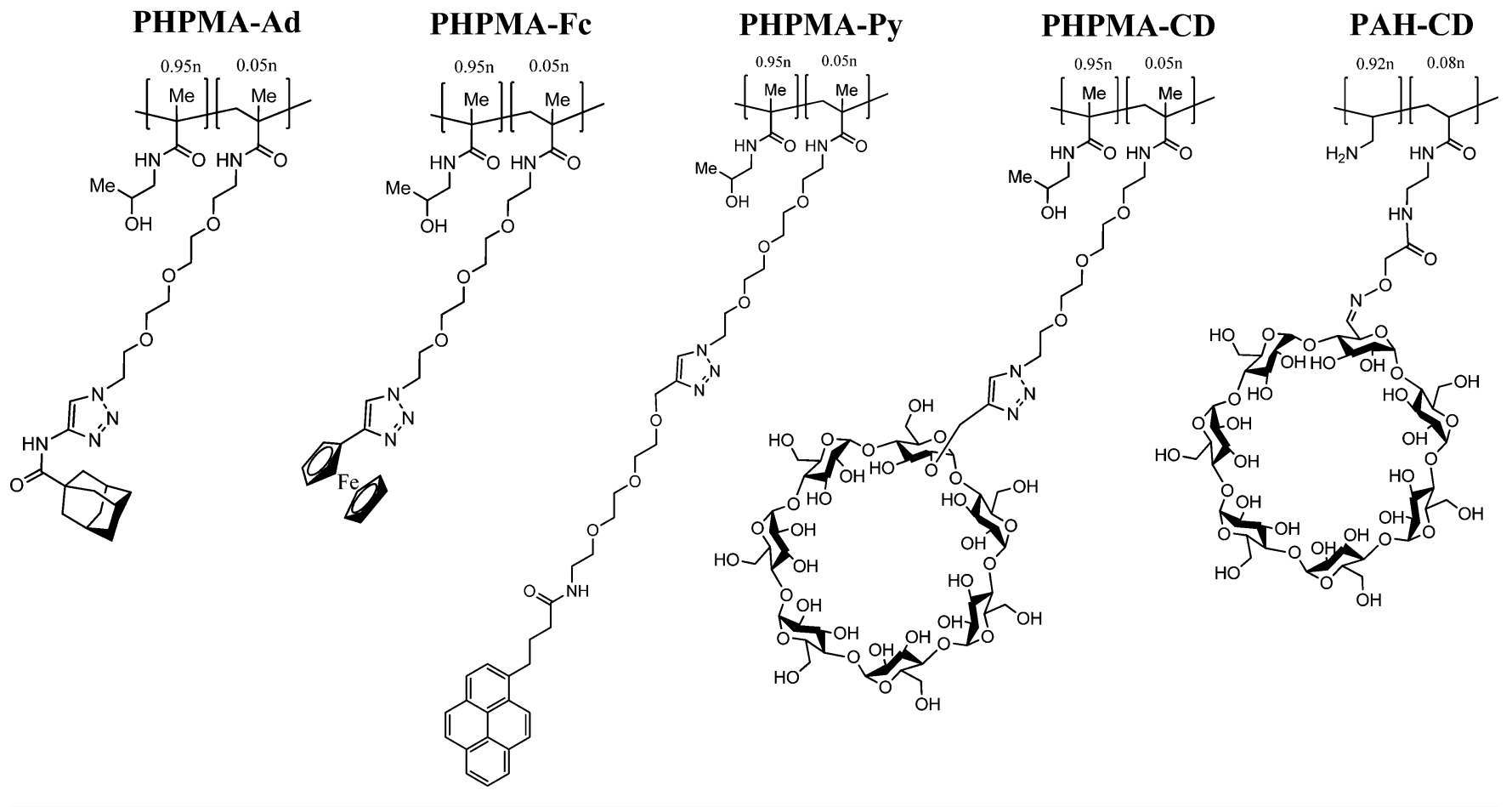

layers through electrostatic interactions ${ }^{8-10}$ is the most prominent example of these types of coatings. Such multilayer films have become extremely popular because it is often believed that step-by-step deposition of polymers leads to a thin coating covering the whole substrate with a nicely stratified structure. Such stratification has been proven for several polyelectrolyte systems, rendering them very appealing for multifunctionalization. ${ }^{1,11-13}$ Yet, full coverage of the substrate is not systematically obtained. Grain- or island-like topographies are often encountered during the multilayer buildup. In 2001, Picart et al. showed that the step-by-step deposition of hyaluronic acid (HA) and poly(L-lysine) (PLL) leads to the formation of islands on silica surfaces during the initial deposition steps. ${ }^{14,15}$ As the number of deposition steps increases, these islands merge and form a gel-like film whose thickness increases exponentially with the number of deposition steps. Similarly poly(vinyl sulfate)/poly(allylamine hydrochloride) ( $\mathrm{PAH}$ ) gives rise to a grainy structure during the initial deposition steps. ${ }^{4}$ Other systems of polymers lead to the formation of islands or grains beyond the early deposition steps. Cini et al. found that poly(sodium phosphate)/PAH leads to an island-like deposit on silicon wafers up to at least 150 deposition steps. ${ }^{16}$ Despite its crucial importance for the entire subsequent multilayer film, only few studies have tried to explain the topography observed (grain- or island-like, droplets, gel-like, etc.) during the initial deposition steps. A recent study by Guillaume-Gentil et al. has focused on this aspect comparing a weakly interacting polyelectrolyte couple (HA/PLL) and a strongly interacting polyelectrolyte couple (polystyrene sulfonate (PSS)/PAH). After a given number of deposition steps, a HA/PLL multilayer can be either a continuous film or an assembly of droplets, depending on the nature of the substrate. ${ }^{17}$ In the case of the PSS/PAH system, a continuous film is obtained independently of the type of the substrate. Comparing their results to recent simulations, GuillaumeGentil et al. proposed an explanation based on the dielectric constant of the substrate, which directly affects the strength of the interactions between the polyelectrolytes and the substrate. According to these simulations, the strength of the monomermonomer interactions strongly influences the topography of the polyelectrolyte multilayer films. ${ }^{18-20}$ Complexation processes between polycations and polyanions can induce a dewetting of the polyelectrolytes from the substrate. For weakly interacting monomers, this dewetting induced the formation of small complexes on the surface leading to droplet or island morphologies.

Multilayer films based on polymers interacting through supramolecular interactions such as hydrogen bonding, ${ }^{21-23}$ ligand-receptor ${ }^{24}$ or host-guest interactions ${ }^{25-28}$ are also widely reported. In particular, the use of $\beta$-cyclodextrins $(\beta$ $\mathrm{CD})$ is an attractive approach because this natural 7-membered sugar ring is cheap, readily available, and is an effective host for several hydrophobic guests. Suzuki et al. showed that electrostatic repulsions between $\mathrm{PAH}$ chains can be overcome through host-guest interactions between ferrocene $(\mathrm{Fc})$ moieties grafted on the $\mathrm{PAH}$ chains and $\beta$-CD homobifunctionalized molecules. ${ }^{25}$ Huskens and co-workers developed layer-by-layer ( $\mathrm{LbL}$ ) assemblies of adamantane (Ad)-functionalized dendrimers and $\beta$-CD-functionalized gold nanoparticles, obtaining well-defined thin multilayer films. ${ }^{29}$ Using nanoimprint lithography ${ }^{30,31}$ or transfer printing, ${ }^{32,33}$ they created 3D supramolecular assemblies with controlled size and geometry. Van der Heyden et al. showed that chitosan chains onto which were grafted $\beta$-CD and Ad moieties, respectively, can be alternately deposited on a gold surface covered with Adfunctionalized self-assembly monolayers. Yet, the film buildup seems to stop after the third deposition step. ${ }^{26} \mathrm{Fc}$ - and $\beta$-CDmodified PAH were reported to form multilayer films and capsules at least until 8 bilayers. ${ }^{27}$ The alternated incubation of the substrate in PAH-CD aqueous and PAH-Fc methanol solution allowed decreasing both the charge repulsion and the polymer dissolution during the film formation. More recently, 
Dubacheva et al. succeeded in an unlimited host-guest multilayer film buildup in aqueous solution by using alternately neutral poly ( $N$-hydroxypropylmethacrylamide) (PHPMA) chains respectively bearing $\beta$-CD (PHPMA-CD) and $\mathrm{Fc}$ (PHPMA-Fc) moieties. ${ }^{28}$ Yet, none of these studies focused on the topography of the formed film. It is well-known that the association constant of $\beta-\mathrm{CD} / \mathrm{Ad}, \beta-\mathrm{CD} / \mathrm{Fc}$ and $\beta-\mathrm{CD} /$ pyrene (Py) complexes is decreasing in this order. ${ }^{34}$ Several studies pointed out that the stability and the association constant of $\beta$ $\mathrm{CD} / \mathrm{Ad}^{35}$ and $\beta$-CD/hydrophobic molecules ${ }^{36-39}$ complexes can be modulated by cosolutes such as salts. Thus, host-guest interactions offer a good opportunity to investigate the influence of the interaction strength between the two polymers on the structure of the resulting step-by-step film.

Here, we investigate the buildup and the topography of PHPMA films formed step-by-step by the deposition of PHPMA bearing $\beta$-CD hosts and hydrophobic guests $(\mathrm{G})$, i.e., Ad, Fc and Py. Depending upon the strength of the inclusion complex, the buildup process is limited for PHPMACD/PHPMA-Py, leading to the formation of a continuous film for PHPMA-CD/PHPMA-Fc and of isolated islands, which do not cover the whole substrate, for PHPMA-CD/PHPMA-Ad. The $\beta$-CD/Fc complex association constant can be tuned by the presence of different types and concentrations of salts, as can be shown by isothermal titration microcalorimetry. Thus, the influence of the inclusion complex strength was studied by building up PHPMA-CD/PHPMA-Fc films in the presence of different sodium salts at different ionic strengths.

\section{MATERIALS AND METHODS}

Chemicals. Poly(allylamine hydrochloride) bearing $8 \% \quad \beta$-CD moieties (named PAH-CD) and poly $(N$-hydroxypropylmethacrylamide) derivatives bearing $5 \%$ guest moieties ( $G=\mathrm{Ad}, \mathrm{Fc}_{\mathrm{c}}$ or Py) and host moieties $\beta$-CD were synthesized as described in the Supporting Information (SI). The PHPMA derivatives were named PHPMA-G (i.e., PHPMA-Fc, PHPMA-Py or PHPMA-Ad) and PHPMA-CD, respectively. These functionalized neutral polymers are represented in Scheme 1. All these PHPMA polymers were prepared by chemical modification of a PHPMA- $\mathrm{N}_{3}$ precursor having the following molecular features: $M_{\mathrm{n}}=34040 \mathrm{~g} / \mathrm{mol}$ and $M_{\mathrm{w}}=92640 \mathrm{~g} / \mathrm{mol}$. The length of the ethylene glycol spacer between the pyrene group and the PHPMA backbone is not similar to that of the other PHPMA derivatives. It was necessary to use a functionalized Py with six ethylene glycol groups to get a PHPMA-Py sufficiently soluble in water for our study. The preparation and characterization of PHPMA-G and PHPMA-CD are given in the SI.

Sodium chloride $(\mathrm{NaCl})$, sodium sulfate $\left(\mathrm{Na}_{2} \mathrm{SO}_{4}\right)$, sodium perchlorate $\left(\mathrm{NaClO}_{4}\right)$, sodium thiocyanate $(\mathrm{NaSCN}), \beta$-CD, and $1,1^{\prime}$-ferrocenedimethanol $\left(\mathrm{Fc}(\mathrm{MeOH})_{2}\right)$ were purchased from SigmaAldrich. Sodium fluoride (NaF) was purchased from Merck, and adamantane-1-carboxylic acid (Ad-COOH) was obtained from Alfa Aesar. All chemicals were used as received. Buffer solutions were prepared at $10 \mathrm{mM}$ HEPES with ultra pure water (Milli-Q Plus system, Millipore, Billerica, MA) with added sodium salts at different ionic strengths. All polymer solutions were prepared at a concentration of $0.1 \mathrm{mg} / \mathrm{mL}$ with HEPES buffer solution containing a sodium salt at different ionic strengths. HEPES buffer and polymer solutions were adjusted at $\mathrm{pH} 7.4$ using a $0.1 \mathrm{M} \mathrm{NaOH}$ solution.

Film Buildup. The PHPMA-G/PHPMA-CD film buildup was performed using polymer solutions and HEPES buffer solution containing the same added sodium salt at the same fixed ionic strength. In order to obtain an anchoring layer, the substrate was first put in contact with a PAH-CD solution for $5 \mathrm{~min}$ followed by a rinsing step of 5 min with HEPES buffer solution. PAH-CD is electrostatically adsorbed on the substrate and so allows immobilizing $\beta$-CD moieties. The PHPMA-G/PHPMA-CD LbL assembly was performed by alternately exposing the substrate for $5 \mathrm{~min}$ to PHPMA-G and PHPMA-CD solutions. An intermediate rinsing step after each polymer deposition was done with HEPES buffer solution for 5 min. The temperature was fixed at $22{ }^{\circ} \mathrm{C}$ during all the experiments.

Quartz Crystal Microbalance with Monitored Dissipation (QCM-D) Measurements. All experiments were performed using quartz crystal microbalance with dissipation monitoring (Q-Sense E4 system equipped with four flow chambers from Q-Sense, Sweden). Monitoring the resonance behavior of piezoelectric oscillators allows measuring the mass adsorbed at the surface of the oscillator in real time. Gold-coated crystals with $5 \mathrm{MHz}(\nu=1)$ resonance frequency were used. The third, fifth, and seventh harmonics $(\nu=3,5$ and 7$)$ at 15,25 , and $35 \mathrm{MHz}$ were also recorded to have a better stability and a higher sensitivity than obtained with the fundamental resonance frequency.

Atomic Force Microscopy (AFM) Measurements. AFM images were obtained in contact mode in liquid conditions with Nanoscope IV from Veeco (Santa Barbara, CA). The samples were kept under liquid (Milli-Q water) for all experiments. The images were carried out with silicon nitride cantilevers, spring constant $0.03 \mathrm{~N} / \mathrm{m}$ (model MSCT-AUHW, Veeco, CA). Deflection and height mode images were scanned simultaneously at a fixed scan rate $(2 \mathrm{~Hz})$ with a resolution of $512 \times 512$ pixels. The film buildup was made on a gold-coated crystal, and the film thickness was measured by using the "scratch" method. The scratches were achieved with a plastic cone tip and were always imaged perpendicular to the fast scan axis. Profilometric section analysis of a scratched film allowed us to precisely determine the thickness of the film over the scanned area. The film thickness, i.e., the $z$ distance between the bare substrate and the surface of the film, is considered as the minimal film thickness covering all the substrate. The mean thickness of the scratched film was determined by measuring the thickness at least on three areas. The film roughness is the root mean square (RMS) given by the AFM software on $15 \times 15$ $\mu \mathrm{m}^{2}$ images. Data evaluations were performed with the NanoScope software version 5.31r1 (Digital Instruments, Veeco).

Isothermal Titration Microcalorimetry (ITC) Measurements. The "heat of reaction" between $\beta$ - $\mathrm{CD}$ and $\mathrm{Fc}(\mathrm{MeOH})_{2}$ (respectively Ad- $\mathrm{COOH}$ ) was measured at $25{ }^{\circ} \mathrm{C}$ by means of isothermal titration microcalorimetry (Nano Isothermal Titration Calorimeter, TA Instruments, New Castle, USA). This microcalorimeter is fitted with two thermostated cells with a volume of $1 \mathrm{~mL}$ : a reference cell containing Milli- $\mathrm{Q}$ water, and a sample cell containing the $\mathrm{Fc}(\mathrm{MeOH})_{2}$ (or Ad-COOH) solution to be titrated. All solutions were degassed $30 \mathrm{~min}$ under vacuum before use. The titration cell was regulated at $25{ }^{\circ} \mathrm{C}$. A typical experiment involved 20 sequential 12.29 $\mu \mathrm{L}$ injections of the $\beta$-CD solution $(8.8 \mathrm{mM})$ into the ITC cell containing the $\mathrm{Fc}(\mathrm{MeOH})_{2}$ (or Ad-COOH) solution $(1.2 \mathrm{mM})$. The concentrations were chosen so that the "mixing molar ratio" between $\beta$-CD and the hydrophobic molecules is equal to 2 at the end of the titration. The injections were made by an automated microsyringe $(250 \mu \mathrm{L})$ ended with a propeller, which stirred the solution at 250 $\mathrm{rpm}$. Two consecutive injections were separated by a resting period of $400 \mathrm{~s}$ to allow the microcalorimeter trace to come back to a baseline corresponding to the absence of any heat flow between the sample cell, in which host-guest interactions took place, and the reference cell, filled with Milli-Q water. For each sodium salt and each salt concentration, the dilution heats were determined by injecting $\beta$ $\mathrm{CD}, \mathrm{Fc}(\mathrm{MeOH})_{2}$, and Ad-COOH solutions into HEPES buffer solution. The binding enthalpy was obtained by subtracting the integrated heat measured during the injection of $\beta$ - $\mathrm{CD}$ in $\mathrm{Fc}(\mathrm{MeOH})_{2}$ (respectively Ad-COOH) from the dilution heat of $\beta$-CD in HEPES, measured at the same salt concentration and $\mathrm{pH}$ value. Finally, the resulting "heat of reaction" was divided by the provided number of $\beta$ CD moles. The first injection was not taken into account in the data analysis. The peak integration was performed with Origin 7.5 after establishment of a linear baseline over 50 points, taken in the time intervals between consecutive $\beta$-CD injections, over the points where the heat flow reached a steady value. In order to obtain the association constant of the complex, the measured heat data were processed assuming the formation of a complex $1: 1{ }^{40}$ Two independent 
experiments were done, and the reproducibility was on the order of $10 \%$.

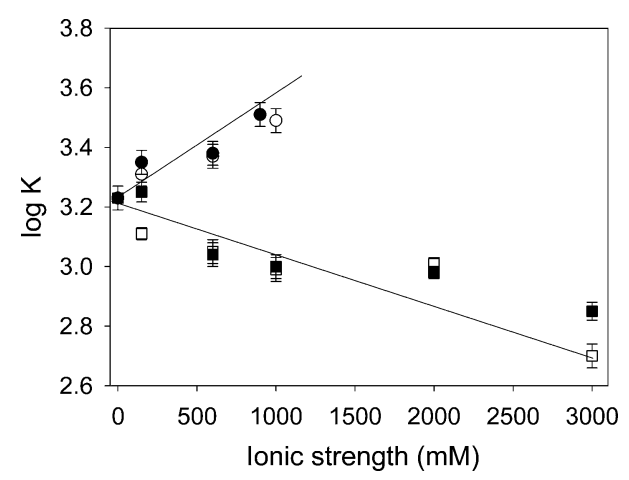

Figure 1. Association constant $(\log K)$ of $\beta-\mathrm{CD} / \mathrm{Fc}(\mathrm{MeOH})_{2}$, measured by ITC, as a function of the ionic strength for $\mathrm{NaF}$ (black circles), $\mathrm{Na}_{2} \mathrm{SO}_{4}$ (white circles), $\mathrm{NaSCN}$ (black squares), and $\mathrm{NaClO}_{4}$ (white squares). ITC experiments were performed in $10 \mathrm{mM}$ HEPES buffer at $\mathrm{pH} 7.4$ and $25{ }^{\circ} \mathrm{C}$. The data represents the mean and the standard deviation of at least two independent experiments. The lines are there to help guide the eye.

\section{RESULTS AND DISCUSSION}

Association Constant of the $\beta$-CD/Guest Complexes. Before the study of the buildup of PHPMA-CD and PHPMA-G multilayer films with different guests, we first determined the association constant of the $\beta-\mathrm{CD} / \mathrm{G}$ complexes in solution. It is well-known that the stability constant of $\beta$ - $\mathrm{CD} / \mathrm{Ad}, \beta-\mathrm{CD} / \mathrm{Fc}$, and $\beta-\mathrm{CD} / \mathrm{Py}$ complexes decreases in this order. $\mathrm{Ad}-\mathrm{COOH}$ and $\mathrm{Fc}(\mathrm{MeOH})_{2}$ were used for ITC experiments. ITC allows gaining access to the association constants $(K)$ of $\beta$-CD/ $\mathrm{Fc}(\mathrm{MeOH})_{2}$ and $\beta$ - $\mathrm{CD} / \mathrm{Ad}-\mathrm{COOH}$, which can be compared to that of the literature. ${ }^{34}$ In $10 \mathrm{mM}$ HEPES buffer solutions at $\mathrm{pH}$ 7.4 and $25{ }^{\circ} \mathrm{C}$ (without additional salt), the constants were estimated at $\log K=4.27 \pm 0.02$ for $\beta$-CD/Ad-COOH and $\log$ $K=3.23 \pm 0.04$ for $\beta-\mathrm{CD} / \mathrm{Fc}(\mathrm{MeOH})_{2}$. These values are in good agreement with the values found in the literature for similar systems: $\log K=4.26$ for $\beta$-CD/Ad-COOH in pure water at $\mathrm{pH} 8.5$ and $25^{\circ} \mathrm{C},{ }^{41}$ and $\log K=3.33$ for $\beta$-CD/ ferrocene carboxylate in $50 \mathrm{mM}$ phosphate buffer at $\mathrm{pH}=8.6$ with $0.1 \mathrm{M} \mathrm{NaCl}$ at $25^{\circ} \mathrm{C} .{ }^{34}$ Due to the poor water solubility of Py, the stability constant of $\beta$-CD/Py complex was not determined in our conditions. This constant is estimated in the literature at 2.69 in water at $25^{\circ} \mathrm{C}^{42}$ To confirm the ability of salt to tune the strength of the host/guest interaction, we determined the association constant of the $\beta-\mathrm{CD} / \mathrm{Fc}(\mathrm{MeOH})_{2}$ complex in different types of salts varying the ionic strength. We used four different sodium salts $\mathrm{Na}_{2} \mathrm{SO}_{4}, \mathrm{NaF}, \mathrm{NaClO}_{4}$, and $\mathrm{NaSCN}$. The results are gathered in Figure 1, where $\log \mathrm{K}$ is presented as a function of the ionic strength. The ionic strength was increased up to $3 \mathrm{M}$ for $\mathrm{NaSCN}$ and $\mathrm{NaClO}_{4}$ but limited to $900 \mathrm{mM}$ for $\mathrm{NaF}$ and $1 \mathrm{M}$ for $\mathrm{Na}_{2} \mathrm{SO}_{4}$ due to the limited solubility of the respective salts (Table S-1 in the SI) or of $\beta$ $\mathrm{CD}$ in the salt. We observed two different trends according to the salt present in solution. On one hand, by increasing the ionic strength of $\mathrm{NaClO}_{4}$ and $\mathrm{NaSCN}$ concentration from 0 up to $3 \mathrm{M}$, the association constant of the $\beta-\mathrm{CD} / \mathrm{Fc}(\mathrm{MeOH})_{2}$ complex decreases from 3.23 down to 2.85 and 2.70, respectively. The influence of the perchlorate $\left(\mathrm{ClO}_{4}^{-}\right)$and the thiocyanate $\left(\mathrm{SCN}^{-}\right)$anions on the stability constant of $\beta$ $\mathrm{CD} / \mathrm{Fc}(\mathrm{MeOH})_{2}$ measured in solution can be rationalized as follows: both $\mathrm{ClO}_{4}^{-43-45}$ and $\mathrm{SCN}^{-44,46}$ anions form $1: 1$ complexes with $\beta-\mathrm{CD}$ (with an association constant of $\log K=$ $1.42^{44}$ and $0.99,{ }^{44}$ respectively) and compete with the formation of the $\beta-\mathrm{CD} / \mathrm{Fc}(\mathrm{MeOH})_{2}$ complex. Indeed, it has been proposed that the inside of the $\mathrm{CD}$ cavity is composed of positively polarized carbon atoms leading to the inclusion of hydrophobic anionic guests ${ }^{47}$ such as the $\mathrm{ClO}_{4}{ }^{-}$and $\mathrm{SCN}^{-}$ anions. A similar decrease of the association constant of $\beta-\mathrm{CD} /$ nabumetone, ${ }^{36} \beta-\mathrm{CD} /$ phenylbenzothiazole derivatives, ${ }^{38}$ and $\beta$ $\mathrm{CD} / 3$-hydroxy-2-naphthoic acid $^{43}$ complexes has been reported in the presence of $\mathrm{ClO}_{4}^{-}$anions.

On the other hand, the increase of the $\mathrm{Na}_{2} \mathrm{SO}_{4}$ and $\mathrm{NaF}$ ionic strength up to, respectively, 1 and $0.9 \mathrm{M}$ induces an increase of $\log K$ of the $\beta$ - $\mathrm{CD} / \mathrm{Fc}(\mathrm{MeOH})_{2}$ complex value up to about 3.5 (Figure 1). Similarly, Harries and co-workers obtained a linear increase of the $\beta$ - $\mathrm{CD} / \mathrm{Ad}$ association constant when increasing the $\mathrm{K}_{2} \mathrm{SO}_{4}$ and $\mathrm{KF}$ concentration. ${ }^{35}$ Sulfate
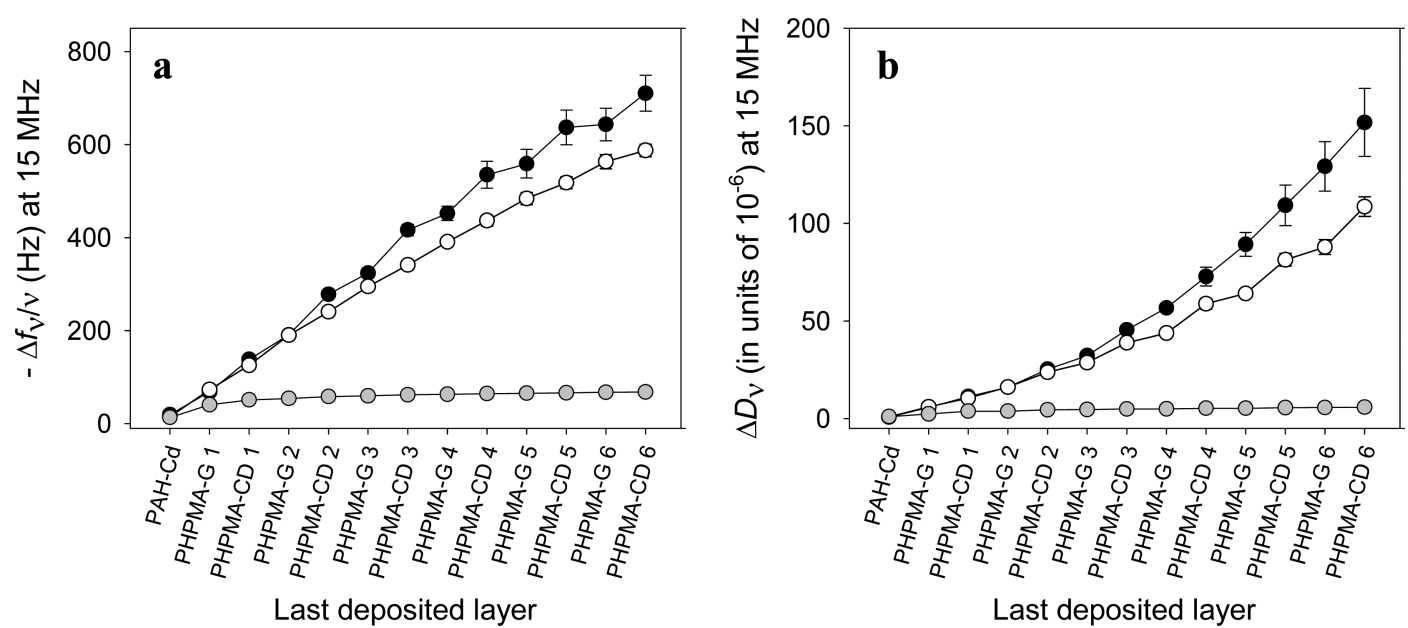

Figure 2. Typical evolution of the normalized frequency shift $-\Delta f_{\nu} / \nu$ (a) and of the energy dissipation $\Delta D_{\nu}(\mathrm{b})$, measured at $15 \mathrm{MHz}(\nu=3)$ by QCM-D, as a function of the last deposited layer for PHPMA-CD/PHPMA-Ad (black circles), PHPMA-CD/PHPMA-Fc (white circles), and PHPMA-CD/PHPMA-Py (gray circles). Polymer solutions were prepared at $0.1 \mathrm{mg} / \mathrm{mL}$ in $10 \mathrm{mM} \mathrm{HEPES}-150 \mathrm{mM} \mathrm{NaCl}$ buffer at pH 7.4. The data represents the mean and the standard deviation of three independent experiments. The values of the standard deviation are smaller or similar size compared to the reported symbol. 


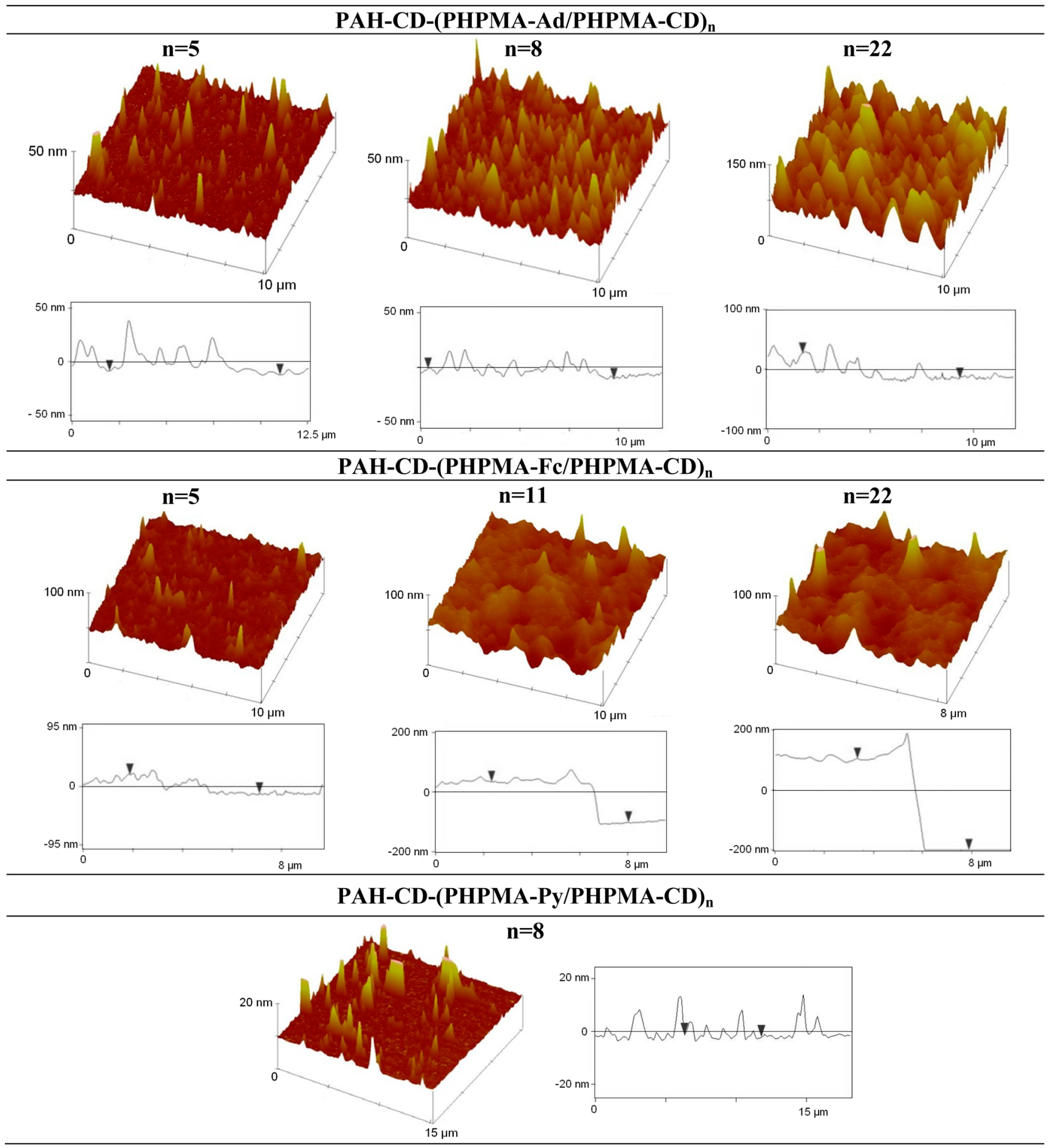

Figure 3. Morphologies and profilometric sections, obtained by AFM in contact mode in the liquid state, of PAH-CD-(PHPMA-Ad/PHPMA-CD) of PAH-CD-(PHPMA-Fc/PHPMA-CD $)_{n}$ at different numbers of deposited bilayers ( $n$ ), and of PAH-CD-(PHPMA-Py/PHPMA-CD) . $_{8}$ Profilometric sections are obtained on scratched films. Polymer solutions were prepared at $0.1 \mathrm{mg} / \mathrm{mL}$ in $10 \mathrm{mM} \mathrm{HEPES} / 150 \mathrm{mM} \mathrm{NaCl}$ buffer at $\mathrm{pH} 7.4$.

$\left(\mathrm{SO}_{4}{ }^{2-}\right)$ and fluoride $\left(\mathrm{F}^{-}\right)$, strongly hydrated anions, do not bind to $\beta$-CD. ${ }^{43,45}$ The increase of the association constant is correlated with the water molecules released from both the $\beta$ $\mathrm{CD}$ cavity and $\mathrm{Fc}(\mathrm{MeOH})_{2}$ upon the formation of the complex. The presence of $\mathrm{SO}_{4}{ }^{2-}$ and $\mathrm{F}^{-}$disturbs the internal structure of water around the $\beta$-CD and its guest, rendering the releasing step of water easier and thus displacing the equilibrium toward the complex formation. ${ }^{48}$ By changing the nature and the concentration of the anion in solution, the association constant between $\beta$-CD and $\mathrm{Fc}(\mathrm{MeOH})_{2}$ can be modulated. After checking this effect in the bulk, we investigated the influence of this interaction strength on the buildup of neutral polymer multilayers based on cyclodextrin/guest interactions.

Neutral Polymer Multilayer Buildup Based on $\beta$-CD/ Guest Interactions. Multilayer assemblies were prepared by alternating depositions of PHPMA-G (i.e., PHPMA-Ad, 
Table 1. Evolution of the Thicknesses and the Roughnesses of PHPMA-CD/PHPMA-Ad and PHPMA-CD/PHPMA-Fc Based Films (AFM Data Extracted from Figure 3) Allowing the Denomination of the Topography of the Films

\begin{tabular}{lcccc} 
& $n$ & $\begin{array}{c}d_{\mathrm{AFM}} \\
(\mathrm{nm})\end{array}$ & $\begin{array}{c}\text { RMS } \\
\text { roughness } \\
(\mathrm{nm})\end{array}$ & $\begin{array}{c}\text { film } \\
\text { topography }\end{array}$ \\
$\begin{array}{c}\text { PAH-CD-(PHPMA-Ad/ } \\
\text { PHPMA-CD })_{n}\end{array}$ & 5 & 11 & 6 & $\begin{array}{c}\text { rough } \\
\text { continuous }\end{array}$ \\
& 8 & 13 & 11 & droplet-like \\
$\begin{array}{c}\text { PAH-CD-(PHPMA-Fc/ } \\
\text { PHPMA-CD })_{n}\end{array}$ & 5 & 31 & 6 & smooth \\
& 11 & 136 & 13 & continuous \\
& 22 & 337 & 21 & \\
\hline
\end{tabular}

PHPMA-Fc, or PHPMA-Py) and PHPMA-CD. The PHPMA backbone being a neutral polymer, the cohesion of the resulting assemblies is only due to the supramolecular host-guest interactions that occur between cyclodextrins and adamantane, ferrocene, or pyrene moieties. Functionalized PHPMA polymers were prepared in two steps: the synthesis of PHPMA-N ${ }_{3}\left(M_{\mathrm{w}}=34040 \mathrm{~g} / \mathrm{mol}, M_{\mathrm{n}}=92640 \mathrm{~g} / \mathrm{mol}\right.$, polydispersity index $(\mathrm{PDI})=2.72$ ) with a grafting ratio of $5 \%$ and its functionalization by the guest through click-chemistry. Using the same batch of PHPMA-N $\mathrm{N}_{3}$ allows us to obtain functionalized PHPMA with different guests and $\beta$-CD having roughly the same length of polymer chains and the same grafting ratio (5\%). The chemical structure of all polymers can be found in Scheme 1, and their preparation is described in the SI.

The buildup of the multilayer films was followed by QCM-D (Figure 2). An anchoring layer of polycationic PAH-CD was first adsorbed. A strong and almost linear evolution of the normalized frequency shift $\left(-\Delta f_{\nu} / \nu\right)$, measured at $15 \mathrm{MHz}$, is observed for both PHPMA-CD/PHPMA-Ad and PHPMACD/PHPMA-Fc systems, reaching roughly 750 and $600 \mathrm{~Hz}$ at the end of the sixth bilayer, respectively (Figure 2a). In contrast, the PHPMA-CD/PHPMA-Py buildup is limited to one bilayer $(40 \mathrm{~Hz})$. The association constant between $\beta$-CD and pyrene ring $\left(\log K=2.69\right.$ in water at $\left.25{ }^{\circ} \mathrm{C}^{42}\right)$ is probably too weak.
After 6 bilayers, the dissipation values reach $150 \times 10^{-6}$ and $110 \times 10^{-6}$ for PHPMA-CD/PHPMA-Ad and PHPMA-CD/ PHPMA-Fc, respectively. These values are relatively large, suggesting that the assemblies are highly hydrated, as was shown in our former study. Indeed, PHPMA-CD/PHPMA-Fc films were found to have $95 \%$ content in water. ${ }^{28}$ To show that the buildup is obtained only due to host-guest interactions, we performed two sets of control experiments: one where only PHPMA-CD was used and the second one where at least one of the host or guest functionalized PHPMA was replaced by PHPMA- $\mathrm{N}_{3}$. We thus followed by QCM the buildup of the following systems: PHPMA-CD/PHPMA-CD, PHPMA-CD/ PHPMA-N ${ }_{3}$, PHPMA-N ${ }_{3}$ PHPMA-Fc and PHPMA-N P $_{3}$ / PHPMA-N $_{3}$ (Figure S-1 in SI). We notice that no buildup of films is obtained in all this cases. The host/guest couple is thus necessary showing that PHPMA-CD/PHPMA-Fc and PHPMA-CD/PHPMA-Ad buildups are only obtained due to the host/guest interactions.

In order to determine the topography of PAH-CD(PHPMA-G/PHPMA-CD) ${ }_{n}$ based films (with G = Ad, Fc and Py), AFM images were performed in contact mode and in liquid state at different numbers of bilayers ranging from 5 up to 22 bilayers. The films were scratched to determine their thicknesses by a profilometric section (Figure 3 ). The film thickness, i.e. the $z$ distance between the bare substrate and the surface of the film, is considered as the minimal film thickness completely covering the substrate. Although similar QCM-D signal evolutions were observed along the buildup of PHPMACD/PHPMA-Ad and PHPMA-CD/PHPMA-Fc films, the topography evolutions are not similar. On one hand, the PHPMA-CD/PHPMA-Ad system leads to extremely rough films mainly constituted of droplets that grow in number and in size with the number of deposition steps (Figure 3, first row). On the other hand, the PHPMA-CD/PHPMA-Fc system forms fairly flat and smooth films whose thickness increases with the number of deposition steps (Figure 3, second row). Concerning the PHPMA-CD/PHPMA-Py system, only few and isolated aggregates are visible on the substrate showing almost no adsorbed polymer (Figure 3, third row). After 22 deposited bilayers, PHPMA-CD/PHPMA-Fc films reach a thickness of about $300 \mathrm{~nm}$ with a roughness of $21 \mathrm{~nm}$ when a
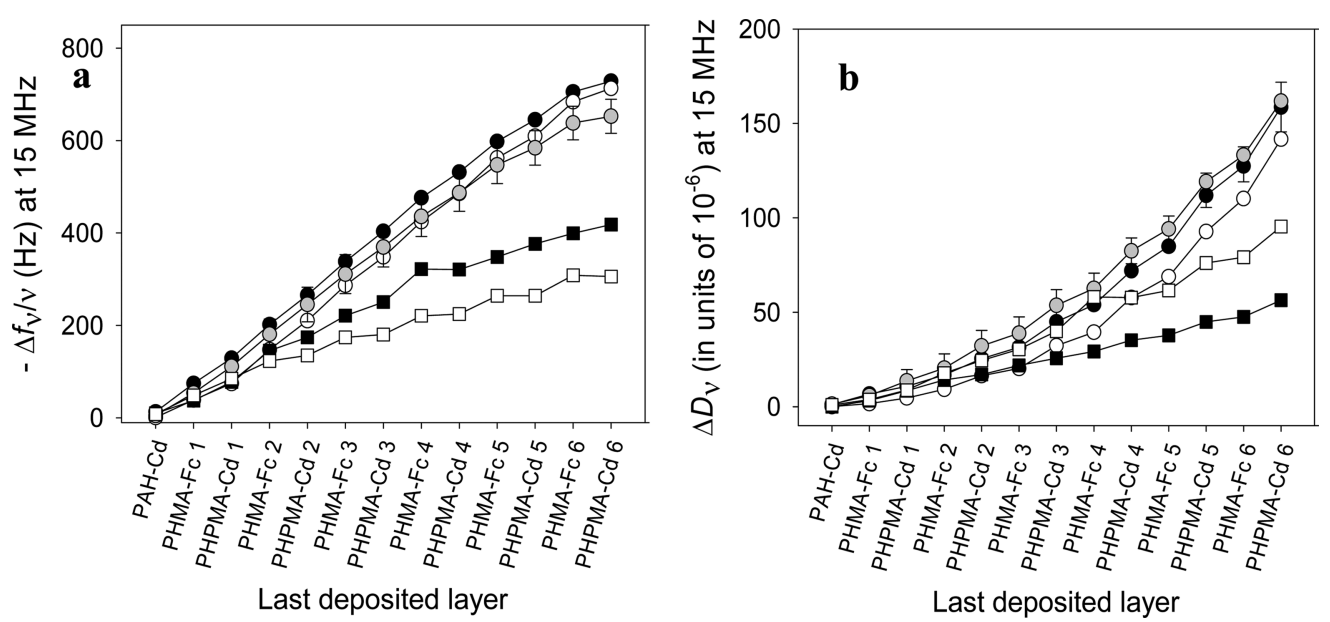

Figure 4. Evolution of (a) the normalized frequency shift $-\Delta f_{\nu} / \nu$ and (b) the dissipation factor $\Delta D_{\nu}$, measured at $15 \mathrm{MHz}(\nu=3)$ by QCM, as a function of the sequence of adsorbed polymer layers during the buildup of PAH-CD-(PHPMA-Fc/PHPMA-CD) 7 in 10 mM HEPES at pH 7.4 without added salt (gray circles) and with $\mathrm{NaF}$ (black circles), $\mathrm{Na}_{2} \mathrm{SO}_{4}$ (white circles), $\mathrm{NaSCN}$ (black squares), and $\mathrm{NaClO}_{4}($ white squares) at the ionic strength of $150 \mathrm{mM}$. 


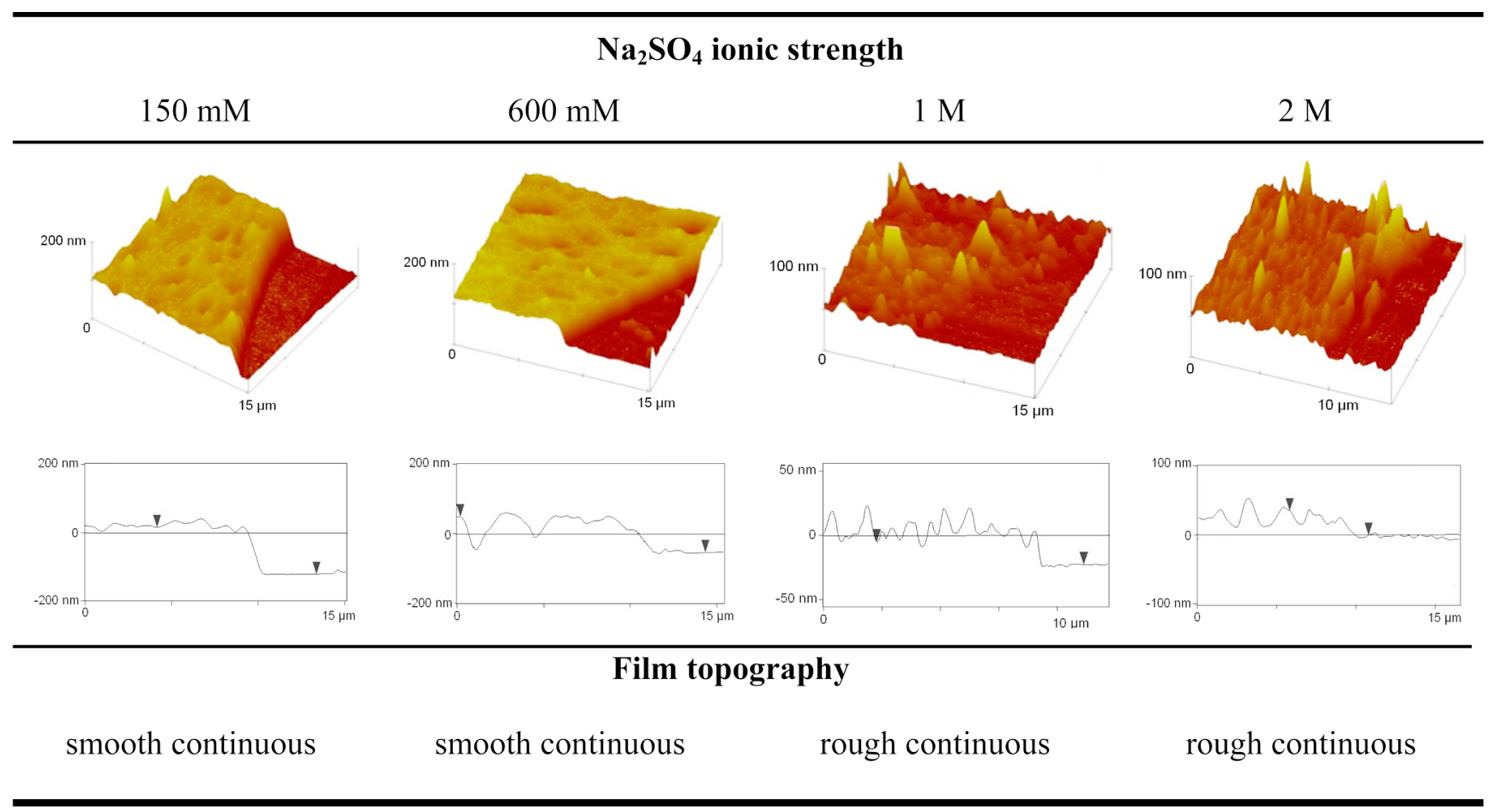

\section{NaSCN ionic strength}

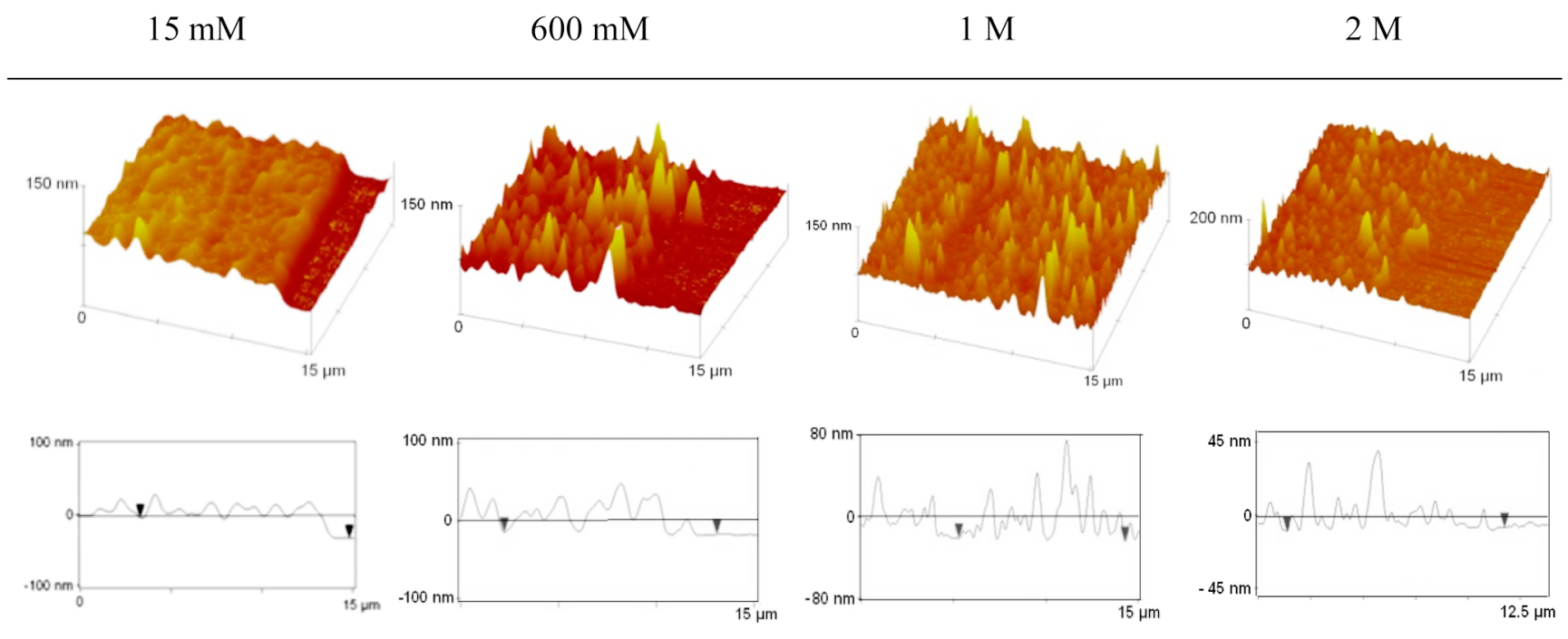

Film topography

rough continuous

droplet-like

droplet-like

isolated aggregates

Figure 5. 3D AFM images and profilometric sections, obtained by AFM in contact mode in liquid environment, of a scratched PAH-CD-(PHPMA$\mathrm{Fc} / \mathrm{PHPMA}-\mathrm{CD})_{7}$ film built in a $10 \mathrm{mM}$ HEPES buffer solution at $\mathrm{pH} 7.4$ in the presence of $\mathrm{Na}_{2} \mathrm{SO}_{4}$ and $\mathrm{NaSCN}$ at different ionic strengths. Polymer solutions were prepared at $0.1 \mathrm{mg} / \mathrm{mL}$.

PHPMA-CD/PHPMA-Ad film has a thickness of $20 \mathrm{~nm}$, with the largest extension of its islands of about $50 \mathrm{~nm}$ (Figure 3 and Table 1). The roughness of PHPMA-CD/PHPMA-Ad films is similar to or higher than the thickness (Table 1), as it is shown in the profilometric section (Figure 3, first row).

All the results reported above were obtained with a polymer concentration of $0.10 \mathrm{mg} / \mathrm{mL}$. To favor the buildup of the films, we investigated the effect of the polymer concentration; two polymer concentrations were further used: 0.05 and 0.50 $\mathrm{mg} / \mathrm{mL}$. Figure S-2 in the SI shows the topography and the profilometric section of the PAH-CD-(PHPMA-Fc/PHPMA$\mathrm{CD})_{n}$ and PAH-CD-(PHPMA-Ad/PHPMA-CD $)_{n}$ films built at polymer concentrations of 0.05 and $0.10 \mathrm{mg} / \mathrm{mL}$ up to $n=22$ bilayers and built at a polymer concentration of $0.50 \mathrm{mg} / \mathrm{mL}$ up 


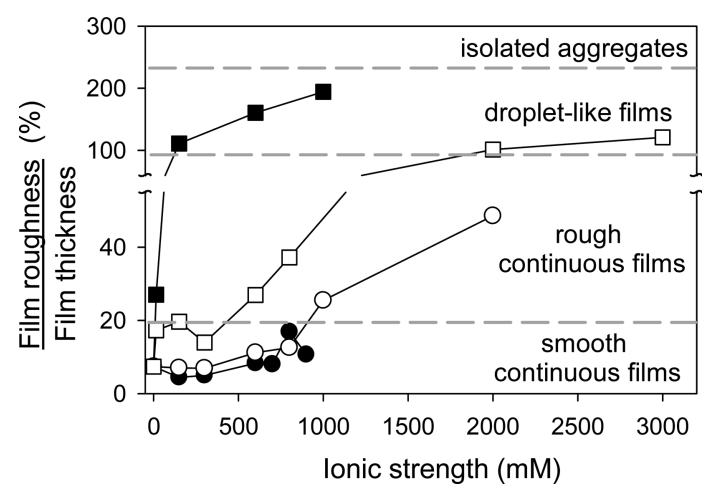

Figure 6. Evolution of the roughness to thickness ratio of a PAH-CD(PHPMA-Fc/PHPMA- $\beta$-CD) ${ }_{7}$ film as a function of $\mathrm{NaF}$ (black circles), $\mathrm{Na}_{2} \mathrm{SO}_{4}$ (white circles), $\mathrm{NaSCN}$ (black squares), and $\mathrm{NaClO}_{4}$ (white squares) ionic strength. The film was built in $10 \mathrm{mM}$ HEPES at $\mathrm{pH} 7.4$ with a polymer concentration of $0.1 \mathrm{mg} / \mathrm{mL}$.

to $n=11$ bilayers. The topography of these films does not depend on the concentration of the polymer solutions used during the buildup process (Figure S-2 in the SI). However, higher polymer concentrations result in larger islands in the case of PHPMA-CD/PHPMA-Ad and thicker films in the case of PHPMA-CD/PHPMA-Fc (Table S-1 in the SI). Based on these results, three types of film topography can be defined: smooth continuous films when the film roughness is below $20 \%$ of the film thickness, rough continuous films when the film roughness is above $20 \%$ of the film thickness, and island-like films when the film thickness is below the film roughness. PHPMA-Ad, PHPMA-Fc, and PHPMA-Py have the same length of polymer chains and the same grafting ratio in hydrophobic groups along the polymer backbone (5\%). The differences in film topography and buildup can only be attributed to the host-guest interaction strength between $\mathrm{Ad}$, $\mathrm{Fc}$, or Py groups and $\beta$-CD. The association constant of Ad and $\beta$-CD being one of the highest reported in the literature, we will qualify the strength of the interaction between PHPMA-Ad and PHPMA-CD as "strong". According to the AFM images, whatever the polymer concentration, strong interactions between neutral polymers through host-guest association lead to a rough continuous film or an island-like film, whereas, regardless of the number of bilayers or of the concentration of the polymers used, intermediate strength interactions (involving Fc groups) lead to a smooth continuous film. Too weak interactions (involving Py derivatives) no longer allow film construction but rather the formation of isolated aggregates.

Influence of the Host-Guest Affinity on Neutral Polymer Multilayer Buildup. First, using ITC, we showed that the interaction of $\beta$-CD with $\mathrm{Fc}(\mathrm{MeOH})_{2}$ can be modulated by changing the nature and the concentration of anions. Then, we observed that PHPMA-CD/PHPMA-Ad multilayers are droplet-like, whereas PHPMA-CD/PHPMA-Fc ones are rather smooth. Based on this observation, our idea was to modulate the affinity of the $\beta$-CD interaction with $\mathrm{Fc}$ by varying the nature of the sodium salt anions and their concentration in the PHPMA solutions used to build PAHCD-(PHPMA-Fc/PHPMA-CD) ${ }_{n}$ films. The polymer concentration was fixed at $0.1 \mathrm{mg} / \mathrm{mL}$. First, the film buildup was performed in $10 \mathrm{mM}$ HEPES buffer at $\mathrm{pH} 7.4$ and at an ionic strength of $150 \mathrm{mM}$ using different sodium salts, namely $\mathrm{NaF}$, $\mathrm{Na}_{2} \mathrm{SO}_{4}, \mathrm{NaSCN}$, and $\mathrm{NaClO}_{4}$ (Figure 4). It appears that the normalized frequency shifts measured by QCM-D corresponding to $\mathrm{F}^{-}$and $\mathrm{SO}_{4}{ }^{2-}$ are significantly higher than those corresponding to films constructed in the presence of $\mathrm{SCN}^{-}$ and $\mathrm{ClO}_{4}{ }^{-}$as the anions of the supporting electrolyte. Without added salt, the buildup of the film is close to the one obtained in the presence of $\mathrm{F}^{-}$and $\mathrm{SO}_{4}{ }^{2-}$. The QCM measurements confirm that the buildup of PHPMA-CD/PHPMA-Fc films can be modulated by the choice of the supporting electrolyte anion.

Furthermore, the topography and the thickness of PAH-CD(PHPMA-Fc/PHPMA-CD) ${ }_{7}$ films were determined by AFM when built in the different types of salts at different ionic strengths. In the absence of salt, the buildup process leads to a smooth continuous film with a thickness of $116 \mathrm{~nm}$ and a roughness of $9 \mathrm{~nm}$ (Figure $\mathrm{S}-3$ in the SI).

By increasing the concentration of $\mathrm{Na}_{2} \mathrm{SO}_{4}$ (or $\mathrm{NaF}$ ), corresponding to an increase of the $\beta-\mathrm{CD} / \mathrm{Fc}$ interaction strength (Figure 1), smooth and continuous films are formed until $800 \mathrm{mM}$ (Figure 5 and Figure S-4 in the SI). A decrease of the film thickness is observed keeping almost the same roughness (Table $\mathrm{S}-3$ in the $\mathrm{SI}$ ). By increasing the concentration of $\mathrm{NaSCN}$ (or $\mathrm{NaClO}_{4}$ ), corresponding to a decrease in the $\beta-\mathrm{CD} / \mathrm{Fc}$ interaction strength (Figure 1 ), the film buildup becomes less and less effective, leading to a smaller film thickness (Figure 5 and Figure S-4 in the SI) and a higher roughness (Table S-3 in the SI). The film topography changes from a smooth continuous film toward a droplet-like film.

The roughness to thickness ratio of PAH-CD-(PHPMA-Fc/ PHPMA-CD $)_{7}$ films as a function of the ionic strength for the four studied salts is represented in Figure 6. By strengthening the host-guest interaction, the topography of the PHPMACD/PHPMA-Fc films changes from smooth and continuous to droplet-like. Whereas for the weakest host-guest interactions ( $\log K=2.7$ at $3 \mathrm{M} \mathrm{NaSCN}$ ), no PHPMA-CD/PHPMA-Fc film buildup is obtained. This was also found for PHPMA-CD/ PHPMA-Py buildup where $\log K=2.69$ for $\beta$-CD/Py in water. This is represented schematically in Scheme 2. These results seem to confirm that the strength of the interaction between the two polymers constituting the film strongly influences the film buildup. Intermediate interaction strength seems to be required to form continuous films whereas if too low, the interaction strength limits the film buildup.

\section{CONCLUSION}

We investigated the influence of the strength of noncovalent host-guest interactions between $\mathrm{CD}$ and Py, Fc, and Ad on the

Scheme 2. Schematic Representation of the Influence of the Ionic Strength on the Topography of PHPMA-CD/PHPMA-Fc Multilayers, via the Tuning of the $\beta$-CD/Fc Association Constant

\begin{tabular}{|c|c|c|c|c|c|}
\hline $\begin{array}{c}\text { Isolated } \\
\text { aggregates }\end{array}$ & & & $\begin{array}{c}\text { rough film } \\
\end{array}$ & smooth filn & : rough film \\
\hline & $\sim 2.7$ & $\sim 3.0$ & $\sim 3.1$ & 3.23 & $\sim 3.4$ \\
\hline
\end{tabular}


structure of PHPMA-CD/PHPMA-Py, PHPMA-CD/PHPMAFc, and PHPMA-CD/PHPMA-Ad films formed in a step-bystep manner. In solution, the strength of the inclusion complex increases in the order $\mathrm{Py} / \beta$ - $\mathrm{CD}<\mathrm{Fc} / \beta$ - $\mathrm{CD}<\mathrm{Ad} / \beta$ - $\mathrm{CD}$. Depending upon this strength, the buildup process is limited to the formation of isolated aggregates for PHPMA-CD/PHPMAPy, leads to smooth continuous films for PHPMA-CD/ PHPMA-Fc, and to droplet-like films, which do not entirely cover the substrate, for PHPMA-CD/PHPMA-Ad. To study in a systematic way the influence of the strength of the host-guest interactions on the topography of the films, PHPMA-CD/ PHPMA-Fc films were built in the presence of different sodium salts at different ionic strengths. For weak host-guest interactions, only isolated aggregates are formed on the substrate. As the interaction strength of the host-guest interactions increases (increase of $\log K$ ), the formed films go through a droplet-like structure, before becoming continuous but rough for stronger interactions. When the interaction is further increased, the films become smooth before becoming rough again at still higher interaction strength. Further studies are needed to verify whether these conclusions apply to other step-by-step constructed polymer films. Moreover, the interactions between the polymers and the substrate should be taken into account to get a general picture of the initial steps of LbL polymer film constructions. Nevertheless, this study constitutes, to our knowledge, the first attempt to rationalize the comprehension of the initial steps of a polymer multilayer buildup as a function of the polymer interaction strength. This study should also trigger new studies on polyelectrolyte multilayers.

\section{ASSOCIATED CONTENT}

\section{S Supporting Information}

Synthesis of the different PHPMA polymers; table of the solubility of the salts used in water; table of thicknesses and roughnesses of PHPMA-Ad/PHPMA- $\beta$-CD and PHPMA-Fc/ PHPMA- $\beta$-CD films built at different polymer concentrations; Buildup of PHPMA-CD/PHPMA-N3, PHPMA-N3/PHPMAFc, PHPMA-N3/PHPMA-N3 and PHPMA-CD/PHPMA-CD films; AFM images and profilometric sections of scratched PAH- $\beta$-CD-(PHPMA-Fc/PHPMA- $\beta$-CD $)_{7}$ films built at different polymer concentrations in $150 \mathrm{mM} \mathrm{NaCl}$; $\mathrm{AFM}$ images and profilometric sections of scratched PAH- $\beta-\mathrm{CD}-(\mathrm{PHPMA}-\mathrm{Fc} /$ PHPMA- $\beta-\mathrm{CD})_{7}$ films without added salt and in the presence of $\mathrm{NaF}$ or $\mathrm{NaClO}_{4}$; table of PAH- $\beta$-CD-(PHPMA-Fc/PHPMA$\beta-\mathrm{CD})_{7}$ film thickness and roughness measured by AFM without added salt and in the presence of added salt at different ionic strengths. This material is available free of charge via the Internet at http://pubs.acs.org.

\section{AUTHOR INFORMATION}

\section{Corresponding Authors}

*E-mail: fouzia.boulmedais@ics-cnrs.unistra.fr; Tel: +33 (0)3 884141 60; Fax: +33 (0)3 88414099.

*E-mail: loic.jierry@ics-cnrs.unistra.fr; Tel: +33 (0)3 884141 47; Fax: +33 (0)3 88414099 .

\section{Notes}

The authors declare no competing financial interest.

\section{ACKNOWLEDGMENTS}

Gwenaëlle Cado is acknowledged for technical assistance on preliminary experiments. Financial support from ANR E-
DETACHPEM (ANR BLAN08-1 315174), ANR ISPES (ANR12-BS08-0006), and Centre National de la Recherche Scientifique is also acknowledged. L.S. thanks the Ministère de l'Enseignement Supérieur et de la Recherche for financial support.

\section{REFERENCES}

(1) Decher, G. Fuzzy nanoassemblies: Toward layered polymeric multicomposites. Science 1997, 277, 1232-1237.

(2) Decher, G.; Schlenoff, J. B. Multilayer Thin Films - Sequential Assembly of Nanocomposite Materials; Wiley-VCH: Weinheim, Germany, 2003.

(3) Lvov, Y.; Decher, G.; Möhwald, H. Assembly, structural characterization, and thermal behavior of layer-by-layer deposited ultrathin films of poly(vinyl sulfate) and poly(allylamine). Langmuir 1993, 9, 481.

(4) Kim, D. K.; Han, S. W.; Kim, C. H.; Hong, J. D.; Kim, K. Morphology of multilayers assembled by electrostatic attraction of oppositely charged model polyelectrolytes. Thin Solid Films 1999, 350, $153-160$.

(5) Caruso, F.; Niikura, K.; Furlong, D. N.; Okahata, Y. 1. Ultrathin multilayer polyelectrolyte films on gold: Construction and thickness determination. Langmuir 1997, 13, 3422-3426.

(6) Delcorte, A.; Bertrand, P.; Wischerhoff, E.; Laschewsky, A. Adsorption of polyelectrolyte multilayers on polymer surfaces. Langmuir 1997, 13, 5125.

(7) Hsieh, M. C.; Farris, R. J.; McCarthy, T. Surface "priming" for layer-by-layer deposition: Polyelectrolyte multilayer formation on allylamine plasma-modified poly(tetrafluoroethylene). Macromolecules 1997, 30, 8453.

(8) Decher, G.; Hong, J. D.; Schmitt, J. Buildup of ultrathin multilayer films by a self-assembly process. Consecutively alternating adsorption of anionic and cationic polyeletrolytes on charges surface. Thin Solid Films 1992, 210/211, 831-835.

(9) Yoo, D.; Shiratori, S. S.; Rubner, M. F. Controlling bilayer composition and surface wettability of sequentially adsorbed multilayers of weak polyelectrolytes. Macromolecules 1998, 31, 4309-4318.

(10) Clark, S. L.; Hammond, P. T. The role of secondary interactions in selective electrostatic multilayer deposition. Langmuir 2000, 16, 10206-10214.

(11) Schmitt, J.; Grünewald, T.; Kjaer, K.; Pershan, P.; Decher, G.; Lösche, M. Internal structure of layer-by-layer adsorped polyelectrolyte films: A neutron and X-ray reflectivity study. Macromolecules 1993, 26, $7058-7063$.

(12) Kharlampieva, E.; Kozlovskaya, V.; Chan, J.; Ankner, J. F.; Tsukruk, V. V. Spin-assisted layer-by-layer assembly: Variation of stratification as studied with neutron reflectivity. Langmuir 2009, 25, 14017-14024.

(13) Félix, O.; Zheng, Z. Q.; Cousin, F.; Decher, G. Are sprayed LbLfilms stratified? A first assessment of the nanostructure of sprayassembled multilayers by neutron reflectometry. C. R. Chim. 2009, 12, 225-234.

(14) Picart, C.; Lavalle, P.; Hubert, P.; Cuisinier, F. J. G.; Decher, G.; Schaaf, P.; Voegel, J.-C. Buildup mechanism for poly(L-lysine)/ hyaluronic acid films onto a solid surface. Langmuir 2001, 17, 74147424.

(15) Picart, C.; Mutterer, J.; Richert, L.; Luo, Y.; Prestwich, G. D.; Schaaf, P.; Voegel, J.-C.; Lavalle, P. Molecular basis for the explanation of the exponential growth of polyelectrolyte multilayers. Proc. Natl. Acad. Sci. U. S. A. 2002, 99, 12531-12535.

(16) Cini, N.; Tulun, T.; Decher, G.; Ball, V. Step-by-step assembly of self-patterning polyelectrolyte films violating (almost) all rules of layer-by-layer deposition. J. Am. Chem. Soc. 2010, 132, 8264-8265.

(17) Guillaume-Gentil, O.; Zahn, R.; Lindhoud, S.; Graf, N.; Voros, J.; Zambelli, T. From nanodroplets to continuous films: How the morphology of polyelectrolyte multilayers depends on the dielectric permittivity and the surface charge of the supporting substrate. Soft Matter 2011, 7, 3861-3871. 
(18) Cerda, J. J.; Qiao, B.; Holm, C. Modeling strategies for polyelectrolyte multilayers. Eur. Phys. J: Spec. Top. 2009, 177, 129148.

(19) Messina, R. Polyelectrolyte multilayering on a charged planar surface. Macromolecules 2004, 37, 621-629.

(20) Dobrynin, A. V. Theory and simulations of charged polymers: From solution properties to polymeric nanomaterials. Curr. Opin. Colloid Interface Sci. 2008, 13, 376-388.

(21) Stockton, W. B.; Rubner, M. F. Molecular-level processing of conjugated polymers. 4. Layer-by-layer manipulation of polyaniline via hydrogen-bonding interactions. Macromolecules 1997, 30, 2717-2725.

(22) Yang, S. Y.; Rubner, M. F. Micropatterning of polymer thin films with $\mathrm{pH}$-sensitive and cross-linkable hydrogen-bonded polyelectrolyte multilayers. J. Am. Chem. Soc. 2002, 124, 2100-2101.

(23) Sukhishvili, S. A.; Granick, S. Layered, erasable, ultrathin polymer films. J. Am. Chem. Soc. 2000, 122, 9550-9551.

(24) Quinn, J. F.; Johnston, A. P. R.; Such, G. K.; Zelikin, A. N.; Caruso, F. Next generation, sequentially assembled ultrathin films: Beyond electrostatics. Chem. Soc. Rev. 2007, 36, 707-718.

(25) Suzuki, T.; Egawa, Y.; Mizukawa, Y.; Hoshi, T.; Anzai, J. I. Construction of positively-charged layered assemblies assisted by cyclodextrin complexation. Chem. Commun. 2002, 164-165.

(26) Van der Heyden, A.; Wilczewski, M.; Labbé, P.; Auzély, R. Multilayer films based on host-guest interactions between biocompatible polymers. Chem. Commun. 2006, 3220-3222.

(27) Wang, Z. P.; Feng, Z. Q.; Gao, C. Y. Stepwise assembly of the same polyelectrolytes using host-guest interaction to obtain microcapsules with multiresponsive properties. Chem. Mater. 2008, 20, 4194-4199.

(28) Dubacheva, G. V.; Dumy, P.; Auzély, R.; Schaaf, P.; Boulmedais, F.; Jierry, L.; Coche-Guerente, L.; Labbé, P. Unlimited growth of hostguest multilayer films based on functionalized neutral polymers. Soft Matter 2010, 6, 3747-3750.

(29) Crespo-Biel, O.; Dordi, B.; Reinhoudt, D. N.; Huskens, J. Supramolecular layer-by-layer assembly: Alternating adsorptions of guest- and host-functionalized molecules and particles using multivalent supramolecular interactions. J. Am. Chem. Soc. 2005, 127, 75947600.

(30) Maury, P.; Peter, M.; Crespo-Biel, O.; Ling, X. Y.; Reinhoudt, D. N.; Huskens, J. Patterning the molecular printboard: Patterning cyclodextrin monolayers on silicon oxide using nanoimprint lithography and its application in 3D multilayer nanostructuring. Nanotechnology 2007, 18, No. 044007.

(31) Ling, X. Y.; Phang, I. Y.; Reinhoudt, D. N.; Vancso, G. J.; Huskens, J. Supramolecular layer-by-layer assembly of 3D multicomponent nanostructures via multivalent molecular recognition. Int. J. Mol. Sci. 2008, 9, 486-497.

(32) Ling, X. Y.; Phang, I. Y.; Reinhoudt, D. N.; Vancso, G. J.; Huskens, J. Transfer-Printing and Host-Guest Properties of 3D Supramolecular Particle Structures. ACS Appl. Mater. Interfaces 2009, 1, 960-968.

(33) Ling, X. Y.; Phang, I. Y.; Schonherr, H.; Reinhoudt, D. N.; Vancso, G. J.; Huskens, J. Freestanding 3D Supramolecular Particle Bridges: Fabrication and Mechanical Behavior. Small 2009, 5, 14281435.

(34) Rekharsky, M. V.; Inoue, Y. Complexation thermodynamics of cyclodextrins. Chem. Rev. 1998, 98, 1875-1917.

(35) Harries, D.; Rau, D. C.; Parsegian, V. A. Solutes probe hydration in specific association of cyclodextrin and adamantane. J. Am. Chem. Soc. 2005, 127, 2184-2190.

(36) Goyenechea, N.; Sanchez, M.; Velaz, I.; Martin, C.; MartinezOharriz, M. C.; Gonzalez-Gaitano, G. Inclusion complexes of nabumetone with beta-cyclodextrins: thermodynamics and molecular modelling studies. Influence of sodium perchlorate. Luminescence 2001, 16, 117-127.

(37) Fini, P.; Castagnolo, M.; Catucci, L.; Cosma, P.; Agostiano, A. The effects of increasing $\mathrm{NaCl}$ concentration on the stability of inclusion complexes in aqueous solution. J. Therm. Anal. Calorim. 2003, 73, 653-659.
(38) Dey, J.; Roberts, E. L.; Warner, I. M. Effect of sodium perchlorate on the binding of 2-(4'-aminophenyl)- and 2-(4'-( $N, N^{\prime}$ dimethylamino)phenyl)benzothiazole with $\beta$-cyclodextrin in aqueous solution. J. Phys. Chem. A 1998, 102, 301-305.

(39) Kotake, Y.; Janzen, E. G. Effect of $\mathrm{pH}$ and salt concentration on bimodal inclusion of a nitroxide by cyclodextrins. J. Am. Chem. Soc. 1989, 111, 7319-7323.

(40) Indyk, L.; Fisher, H. F. Theoretical aspects of isothermal titration calorimetry. Methods Enzymol. 1998, 295, 350-364.

(41) Eftink, M. R.; Andy, M. L.; Bystrom, K.; Perlmutter, H. D.; Kristol, D. S. Cyclodextrin inclusion complexes - Studies of the variation in the size of alicyclic guests. J. Am. Chem. Soc. 1989, 111, 6765-6772.

(42) Blyshak, L. A.; Warner, I. M.; Patonay, G. Evidence for noninclusional association between $\alpha$-cyclodextrin and polynuclear aromatic hydrocarbons. Anal. Chim. Acta 1990, 232, 239-243.

(43) Yi, Z. P.; Zhao, C. C.; Huang, Z. Z.; Chen, H. L.; Yu, J. S. Investigation of buffer-cyclodextrin systems. Phys. Chem. Chem. Phys. 1999, 1, 441-444.

(44) Rohrbach, R. P.; Rodriguez, L. J.; Eyring, E. M. An equilibrium and kinetic investigation of salt-cycloamylose complexes. J. Phys. Chem. 1977, 81, 944-948.

(45) Chamberlain, R. V.; Slowinska, K.; Majda, M.; Buhlmann, P.; Aoki, H.; Umezawa, Y. Electrostatically-induced inclusion of anions in cyclodextrin monolayers on electrodes. Langmuir 2000, 16, 13881396.

(46) Sasaki, M.; Ikeda, T.; Mikami, N.; Yasunaga, T. Kinetic study on inclusion compound formation reaction of $\beta$-cyclodextrin polymer with $\mathrm{SCN}^{-}$using the electric field pulse technique. J. Phys. Chem. 1983, 87, 5-6.

(47) Kano, K.; Tanaka, N.; Minamizono, H.; Kawakita, Y. Tetraarylporphyrins as probes for studying mechanism of inclusioncomplex formation of cyclodextrins. Effect of microscopic environment on inclusion of ionic guests. Chem. Lett. 1996, 925-926.

(48) Gurnev, P. A.; Harries, D.; Parsegian, V. A.; Bezrukov, S. M. The dynamic side of the hofmeister effect: A Single-molecule nanopore study of specific complex formation. ChemPhysChem 2009, 10, 14451449. 